Article

\title{
Smart Waste Monitoring System as an Initiative to Develop a Digital Territory in Riobamba City
}

\author{
Diego Veloz-Cherrez ${ }^{1, *}$, Raúl Lozada-Yanez ${ }^{1}$, Jesús Rodríguez ${ }^{1}$, Paúl Mayorga ${ }^{2}$ and \\ Johana Panchi ${ }^{2}$ \\ 1 Department of Informatics and Electronics, Escuela Superior Politécnica de Chimborazo, Riobamba 060150, \\ Ecuador; raul.lozada@espoch.edu.ec (R.L.-Y.); jesus.rodriguez@espoch.edu.ec (J.R.) \\ 2 Facultad de Ciencias Administrativas, Univercidad Central Del Ecuador, Riobamba 060150, Ecuador; \\ paul19921@hotmail.es (P.M.); johany1595@hotmail.com (J.P.) \\ * Correspondence: diego.veloz@espoch.edu.ec; Tel.: +593-9872-14582
}

Received: 23 March 2020; Accepted: 20 April 2020; Published: 22 April 2020

\begin{abstract}
Digital territories focus on community transformation through sustainable development, saving resources in local governments, bridging the digital gap, and using technology to build smart infrastructure. This article presents the design and implementation of a smart system, called the Waste Treatment System (WTS), for controlling parameters of waste decomposition in the trash bins installed in Riobamba city (Ecuador). The prototype allows monitoring in real time both the amount of waste and the level of rottenness of garbage by means of the measurement of different parameters that indicate the characteristics of the leachates generated inside. The motivation of this work was to yield an efficient solution to urban waste treatment that optimizes resources in the collection process by providing real-time information to improve collection frequency vehicles and also reduce emissions by the decomposition of organic waste. The tests allowed assessing technical aspects such as the maximum coverage of wireless communication, the transmission channel capacity for each prototype, the data-processing requirements, and other more particular parameters such as the production of leachates due to the frequency of collection and the environmental conditions, which will be useful in future work on environmental impact.
\end{abstract}

Keywords: smart waste system; smart cities; digital territories; waste collection; waste monitoring; smart urban infrastructure

\section{Introduction}

Cities with a high level of development or with highest population density are the ones that generate most of the garbage globally. Bombay produces 11,000 tons of waste daily. Meanwhile, China's waste increases at twice the rate of the population increase. New York City generates the most waste worldwide (around 33 million tons per year), and Mexico City follows with 12 million tons per year [1]. To solve this problem, Afula city (Israel) was one of the pioneers in implementing smart containers that report in real time when they are full and communicate with the entities in charge for collecting garbage [2]. As the population grows, it stands to reason that much more waste will be generated and it is expected to reach 2.2 trillion tons per year globally by 2025 [3].

In Ecuador, one of the shortcomings has been the waste control and collection, which is why the Ministry of the Environment settled on a collection program, implementing containers on the streets, called Eco-tachos [4]. However, there are unwanted effects that have occurred with this implementation such as the proliferation of rodents and flies, due in part to the excessive accumulation of trash inside and outside the containers. The risk increases since these animals are carriers of Acute Diarrheal Diseases (ADD). Data presented by Regional Health Management of Lima (Peru) report an increase of up to $4 \%$ in the incidence of ADD per week [5]. 
On the other hand, there is no correct control of garbage collection and pollution in Riobamba (Ecuador), where it is becoming increasingly common to see an increase in contamination on the streets. For this reason, the Department of Environmental Management, Health and Hygiene of the Decentralized Autonomous Municipal Government (GAD) of Riobamba, executed the first stage of the Eco-tachos project in 2015, placing 500 containers in different neighborhoods of the city, which covered only $60 \%$ of the waste collection [6]. In the second stage, 1050 Eco-tachos were implemented [7]. Despite these efforts, many containers in different sectors fill up with garbage and become an infectious focus due to the poor planning of waste collection frequency, which contributes to contamination of the surrounding environment and attracts insects and rodents. This problem becomes even more critical due to demographic growth and the trend of concentration of the majority of the population in urban areas, in pursuit of better conditions of progress, education, and job opportunities [8].

Human migration to urban areas has led to the search for sustainable, environmentally friendly, and scalable cities becoming smart cities in order to consume their natural and municipal resources more efficiently [9]. The White Paper on Digital Territories in Ecuador is a guide that presents strategies and best practices for the development of smart cities through their local governments generating policies that guarantee accessible and timely services for citizens, which improves their quality of life by means of the correct use of technology as a fundamental pillar of transformation.

There are countless works aimed at improving people's quality of life by creating smart cities, such as the energy efficiency of public lighting, traffic control, or control of residential energy consumption [10-12]. Nevertheless, smart waste collection is one of the essential axes defined to strengthen the provision of public services and the improvement of the quality of life in a digital territory [13]. In [14], components are defined to build urban environments in smart cities, among which stand out the "Control of Waste and Pollution" as one of the main factors required to cement a future smart infrastructure.

Due to these reasons, the main objective of this work is to design and implement a prototype that autonomously monitors and controls the level of accumulation of waste and determines which parameters affect the most for leachate generation inside containers. In this way, this project can improve the process of waste collection and contribute to the transformation of the city processes by making innovation as the path to the development of a smart and digital city $[8,9,13]$. Unlike other similar projects that have even incorporated video transmission or mobile communication [15,16], this research proposes the implementation of a system with open software that uses a wireless communication with free license and does not require expenses for data transmission or high consumption of bandwidth. Although there are not enough studies that analyze costs of implementation and operation or costs by broadcasting through mobile infrastructure, using high-definition cameras for video streaming or using mobile communications for connectivity make the high consumption of resources evident.

This system has been developed with different modules that work at the $2.4 \mathrm{GHz}$ frequency to take advantage of the free use of this band. These modules allow controlling different processes such as the capture of the sensors, communication with the main processing card, and the transmission of the data collected to the cloud server and with a communication based on IoT (Internet of Things).

\section{Materials and Methods}

There are several works in which different methodologies were proposed for waste management system implementations. For example, [17] shows a study over more than 10 years, comparing 32 investigations that implement different technologies, physical infrastructure, software, and applications. This research sums up a taxonomy to implement a waste management system in smart cities that focuses on three main factors: (1) a physical infrastructure, (2) IoT technology, and (3) data analysis software. The design of this prototype is based on this taxonomy and allows waste monitoring in a trash container in Riobamba (Ecuador). Nevertheless, different low-cost technologies have been used to achieve efficient communication in resources consumption and efficient usage of the communication 
channel. The prototype design consists of three main parts, as shown in Figure 1: Sensor Node (NS), Gateway Node (NG), and Storage and Monitoring Node (NAM), which will be described in detail later.

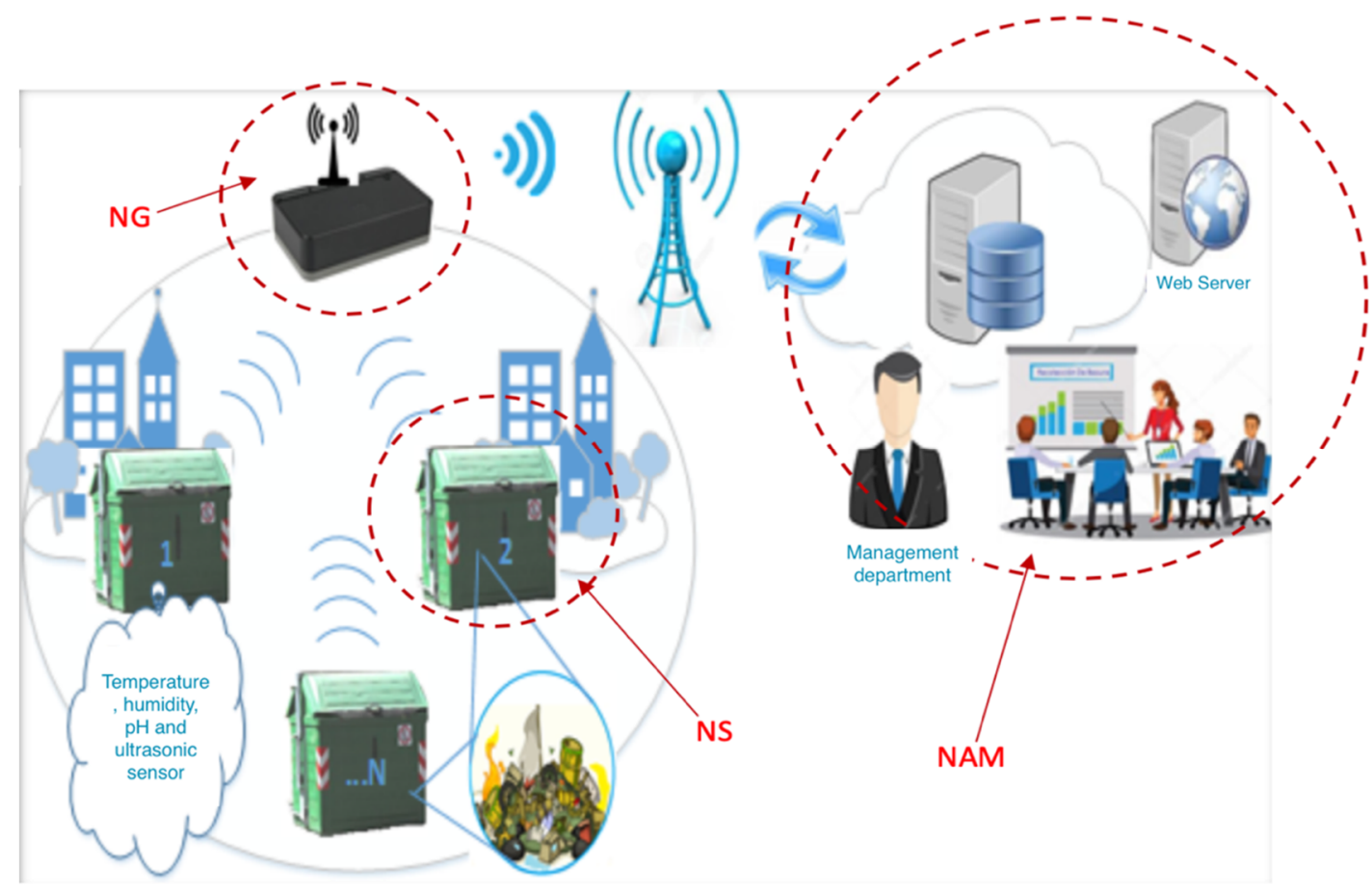

Figure 1. General system structure.

\subsection{Specifications}

Several requirements have been identified that must be considered to contribute an effective and uninterrupted communication, which are detailed below:

- IPxx protection for each device.

- Autonomous electrical supply.

- Must not limit the mobility and modifications of the Eco-tacho (mainly by the waste collection vehicle)

- $\quad$ Prolonged energy storage (48 h).

- Must be scalable.

- Ideal location of the device to avoid easy removal.

- Sending information in real time periodically.

- Measuring temperature, humidity level, and $\mathrm{pH}$ levels.

- Identification of each Eco-tacho in order to improve frequency collection.

These requirements have been considered due to the needs of the technical department of the municipality of Riobamba and also based on some previous studies. For instance, the choice of parameters was based on some studies $[18,19]$, which conclude that temperature, moisture, and $\mathrm{pH}$ level are the principal factors for waste decomposition and the course of action in all biological process and hence leachate generation [20].

Hardware considerations were made based in the conception of the project. Wireless communication with long-range coverage was needed because of the distance between Eco-tachos and Gateway Nodes (NG). NRF modules (Nordic Semiconductor Radio Frequency chip) were considered for both transmitting information from sensor measures and because of compatibility with the mainboard controller. In Figure 1, the general conception of the system is shown and indicates the relationship between all nodes and their interaction through the wireless network, forming a star topology that will 
transmit in real time the state of the Eco-tacho, as well as improving collection by reporting the level of accumulation inside.

On the other hand, when sensor parameters have been captured, this information is processed by a microcontroller card and sent to a cloud server through Internet. Riobamba has a public WIFI network, as part of its digital city plan, which will be used for the Internet access that the prototype needs. This allows communication to be free, and there is no need for surcharges, as would happen with other technologies such as access to the web through the mobile platform. For this reason, Wi-Fi has been used as the communication standard for Internet connectivity. Table 1 shows a comparison between two similar Radio Frequency (RF) modules:

Table 1. Radio frequency module comparison.

\begin{tabular}{ccc}
\hline Features & NRF24L01 + PA + LNA Module & NRF 905 Module \\
\hline Voltage & $1.9-3.6 \mathrm{~V}$ & $1.9-3.6 \mathrm{~V}$ \\
Data rate & $2 \mathrm{Mbps}$ & $50 \mathrm{Kbps}$ \\
Number of channels & 6 & 6 \\
Frequency & $2.4-2.5 \mathrm{GHz}$ & $2.4-2.5 \mathrm{GHz}$ \\
Operating temperature & $-45 \mathrm{to}+70^{\circ} \mathrm{C}$ & -45 to $+85^{\circ} \mathrm{C}$ \\
Sensitivity & $-95 \mathrm{dBm}$ & $-100 \mathrm{dBm}$ \\
Range coverage & $1000 \mathrm{~m}$ & $300 \mathrm{~m}$ \\
\hline
\end{tabular}

NRF24L01 module was chosen due to its better features versus NRF905. Similarly, Table 2 shows a comparison for Wi-Fi module selection.

Table 2. Wi-Fi module comparison.

\begin{tabular}{ccc}
\hline Features & ESP32 & ESP8266EX \\
\hline Voltage & $2.3-3.6 \mathrm{~V}$ & $2.5-3.6 \mathrm{~V}$ \\
Amperage & $1200 \mathrm{~mA}$ & $80 \mathrm{~mA}$ \\
Price & Around US $\$ 5.00$ & Around US $\$ 1.5$ \\
Operating temperature & -40 to $150{ }^{\circ} \mathrm{C}$ & -40 to $125^{\circ} \mathrm{C}$ \\
Standards & Bluetooth and Wi-Fi $802.11 \mathrm{n}(2.4 \mathrm{GHz})$ & $802.11 \mathrm{~b} / \mathrm{g} / \mathrm{n}$ \\
& & $(2.4 \mathrm{GHz})$ \\
\hline
\end{tabular}

As it can be seen in the table above, ESP8266EX was chosen because of its low-power consumption, lower price, and Wi-Fi standard compatibility.

\subsubsection{Sensor Node (NS)}

This is the node that is placed inside each Eco-tacho and is in charge of collecting all the information generated by the sensors to send it to the Gateway node using an NRF24L01 module. The sensors that are part of this node for data acquisition include temperature, humidity, ultrasonic for the level of accumulation, and a pH sensor, as it can be seen in Figure 2. Photovoltaic panels are used to supply energy, allowing constant operation. 


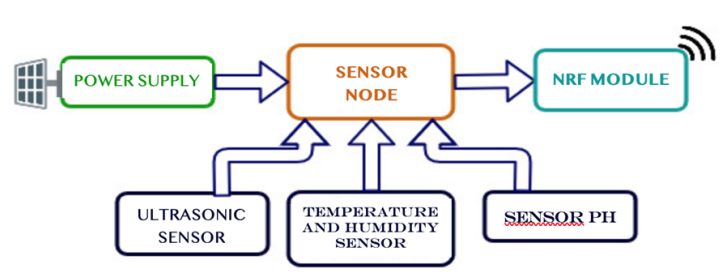

(a)

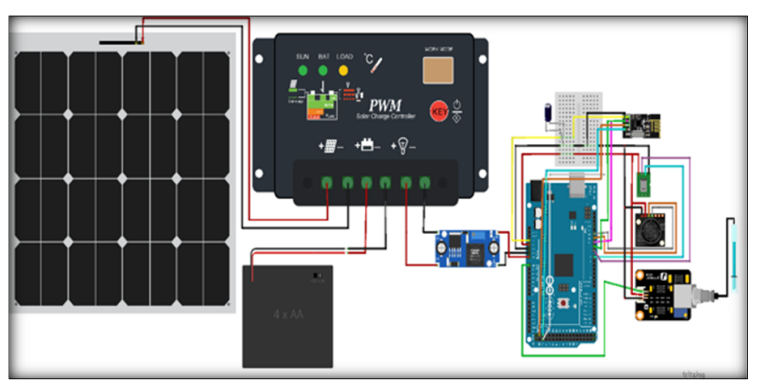

(b)

Figure 2. Structure of the Sensor Node (NS): (a) NS block diagram. (b) NS connection diagram.

\subsubsection{Gateway Node (NG)}

Figure 3 shows the NG components. The NRF24L01 module receives the information coming from NS, followed by the sending block that maintains wireless communication through the ESP8266 Wi-Fi module in order to send all information through the Internet and communicate with the Nodo de Almacenamiento y Monitoreo (NAM) module.

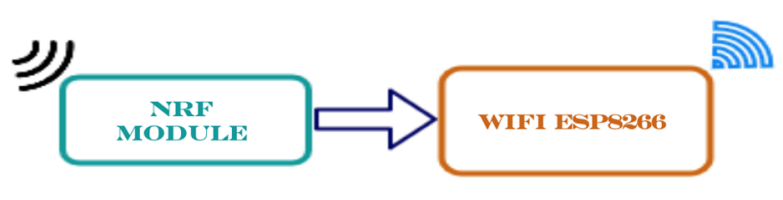

(a)

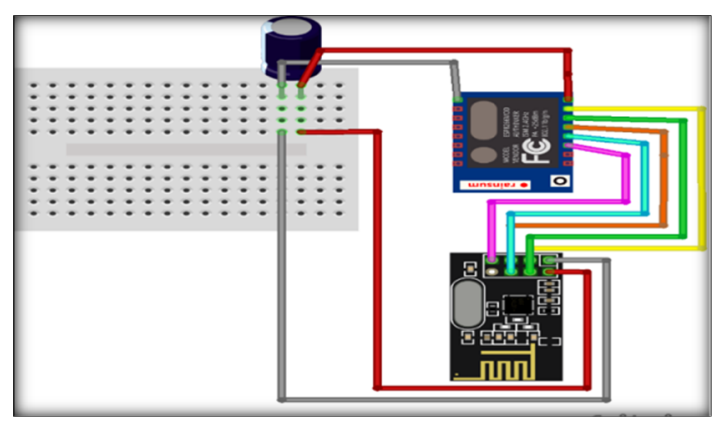

(b)

Figure 3. Structure of the gateway node (NG): (a) NG block diagram. (b) NG connection diagram.

\subsubsection{Nodo de Almacenamiento y Monitoreo (NAM)}

NAM is formed by a web page, cloud server, and database, and it has the function of processing and storing all the data acquired by the NS and sent through the NG. It keeps each record of temperature, humidity, pH levels, and the frequency that the Eco-tacho is filled. Likewise, this node will also allow warnings when the Eco-tacho is close to being full and can be configured to transmit alerts regarding the other parameters. Finally, this information is displayed on a web page that can be accessed by users. Figure 4 shows the architecture of NAM.

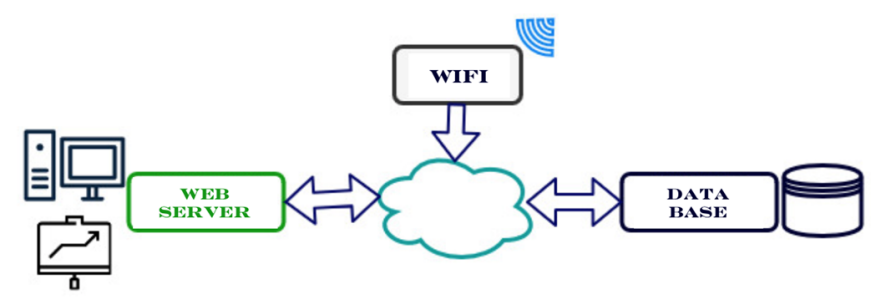

Figure 4. Nodo de Almacenamiento y Monitoreo (NAM) block diagram.

The prototype must be placed strategically to avoid unwanted removals or any damage caused by the movement that the collection vehicle may produce. A 3D design of the Eco-tacho was carried out to determine the proper location of the internal and external elements, as shown in Figure 5. 


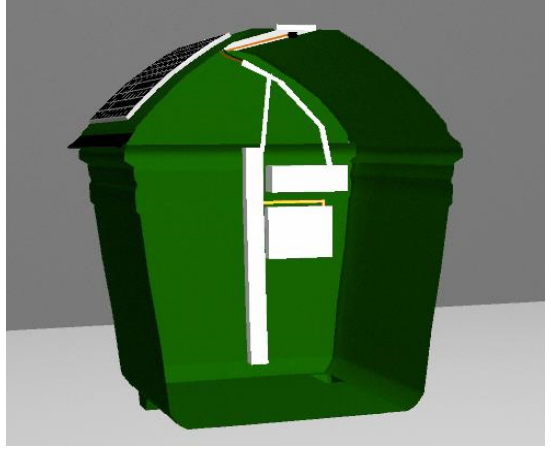

(a)

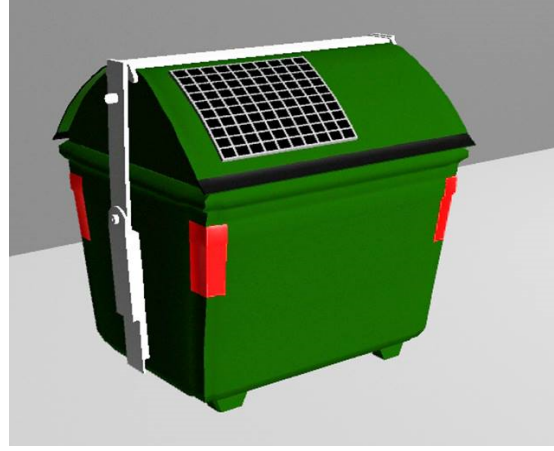

(b)

Figure 5. (a) Internal 3D image of module distribution. (b) External 3D image.

The device was located inside the Eco-tacho using an IP 65 protection box and covered with metal blocks to prevent the ingress of dust, water, and greater security, as depicted in Figure 5a. A new container cover was designed and made for solar panel placing, as shown in Figure 5b.

We have taken some considerations about security against theft or prototype damage. Ecuador has a camera surveillance system called ECU911 that is a system formed by more than $4700 \mathrm{HD}$ video cameras, located in strategical zones for the safety of citizens [21]. Riobamba is part of this system with video cameras operating in its urban zone. For security reasons, the specific number of cameras and locations where they are implemented cannot be published. However, the type of cameras implemented in this system are Pan-Tilt-Zoom, which are cameras that have movement and a powerful zoom to achieve wide coverage [22] (p. 42588). The idea is to implement the prototype in containers that are located in the coverage area of this camera surveillance system.

Meanwhile, the container structure was modified in order to protect the prototype, both inside and outside, as Figure 5 shows. Metal ducts and a double wall were installed inside to prevent the elements from being easily removed and to protect against damage. The position for the solar panel was also studied in order to prevent damages. Lids are retracted behind the container when a truck collector is picking up the garbage, and they are not involved in waste collection, as it can be seen in Figure 6. The container lid was also reinforced to support and protect the solar panel.

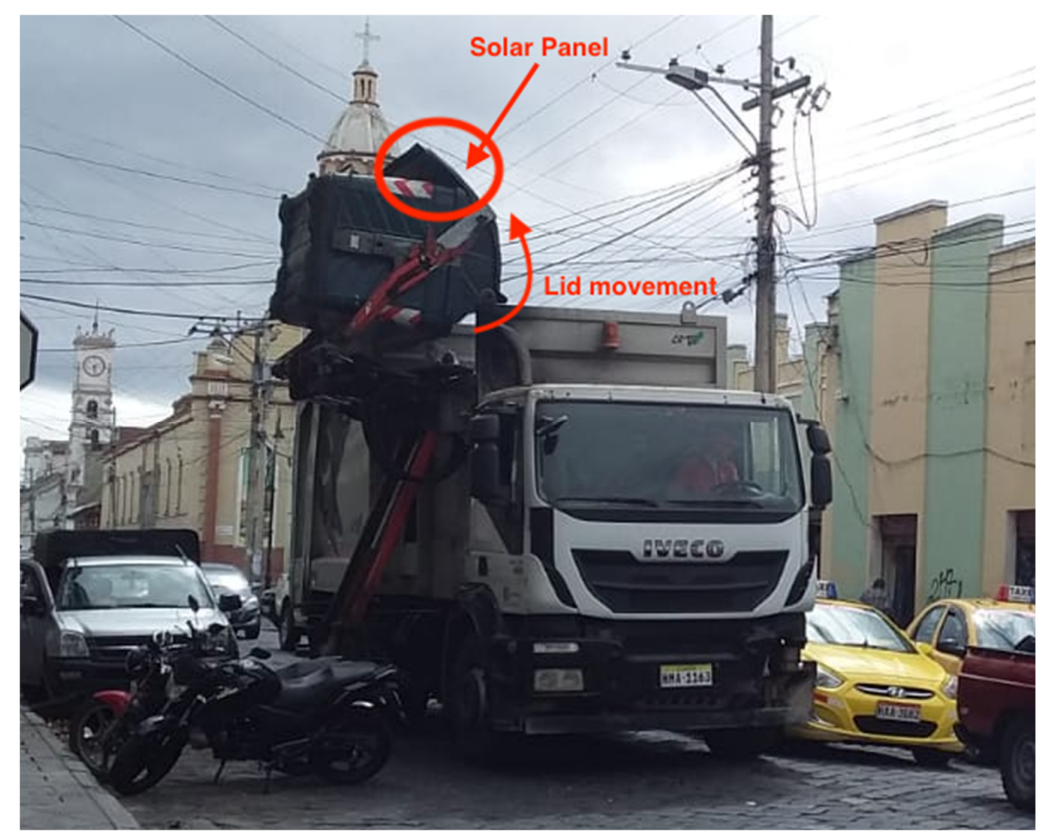

Figure 6. Waste collection process [23]. 


\subsection{Implementation}

The complete circuit of the project was simulated before implementation. Figure 7 shows the performance of the prototype and the right connection diagram.

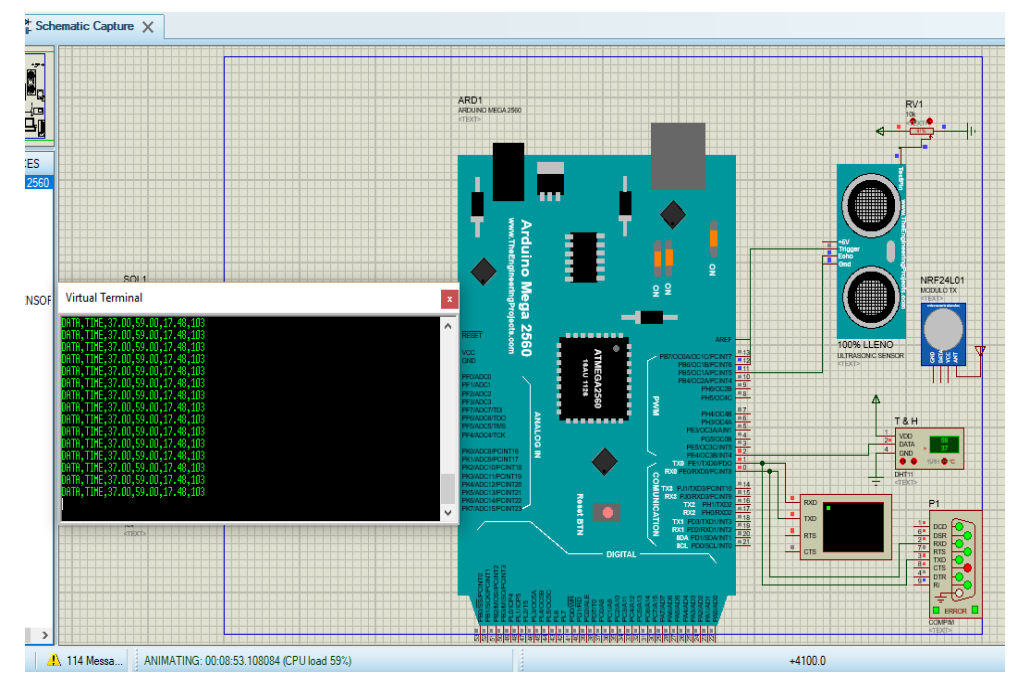

Figure 7. NS and Gateway Nodes (NG) operation.

The prototype was implemented on the Escuela Superior Politécnica de Chimborazo (ESPOCH) campus, in Riobamba. The first stage was sensors calibration so that they can accurately acquire the parameters. The other stages are detailed below.

\subsubsection{Database Implementation}

The database was designed in MySQL, since both Xampp software and 000Webhost work under the same language. The database was called "sensortachoriob" Figure 8. It was designed based on an entity-relationship model in which all data have coherence with each other, creating three main tables called "ecotachos", "medidas", and "usuarios" with their own attributes.

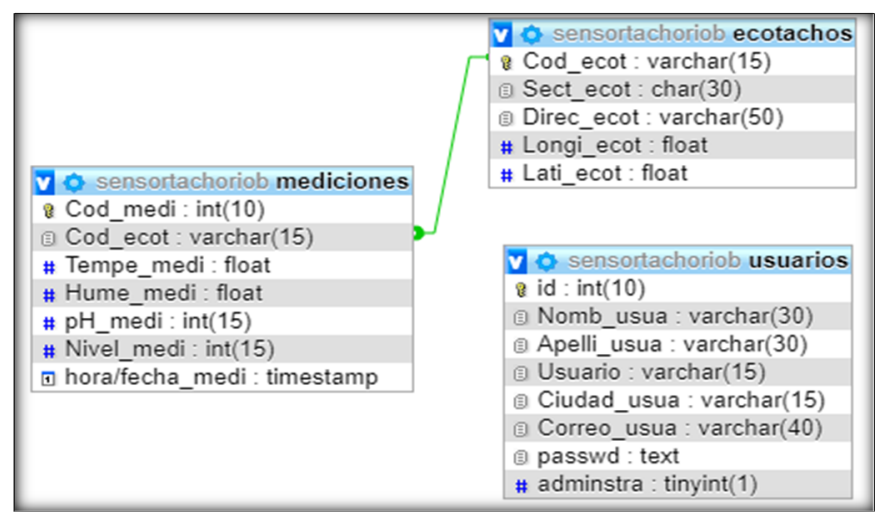

Figure 8. Webhost server.

\subsubsection{Web Page Implementation}

The web page consists of several hyperlinked pages. The main page has a menu with 5 options: user registration, parameter measurements, information about the project, information about the Eco-tachos location, and a map site. The parameter measurements page, depicted in Figure 9, shows information sent by the prototype in real time and allows receiving alerts from the parameters defined 
as limits for control automatically, both of contamination originated by decomposition and waste accumulation in order to improve frequency collection.

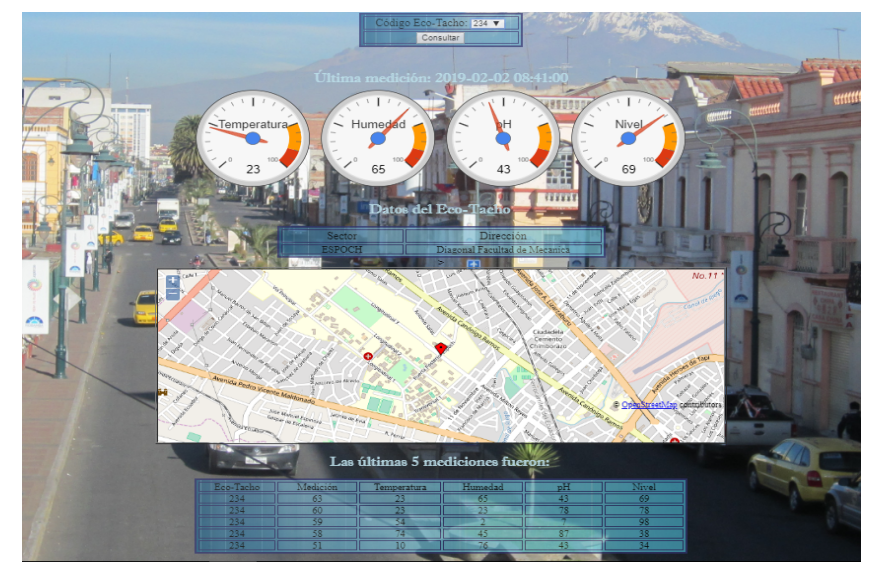

Figure 9. Parameter measurement page.

On the other hand, the user registry allows assigning a user and password to each person in charge of a collection vehicle to have control of the containers installed in the area of their responsibility. They will receive all the alerts generated by the devices about the status of the containers under their responsibility when logging in through the website. The location of each Eco-tacho was also considered through geolocation applications; in this case, it was linked to Google Maps to help users in their decision-making on collection routes. Unlike other projects, there was no need to implement a GPS system in each container and continuously measure their locations, since each one has a designated and fixed location.

If necessary, users could be assigned to the personnel of environmental control entities so that they can monitor the levels of waste contamination and make preventive and corrective decisions depending on critical level of each area.

\subsubsection{Server Implementation}

XAMPP software Figure 10, which is a free Apache distribution containing MariaDB, PHP, and Perl, was chosen to implement the server for running tests and data collection. Once the correct operation of the web page and the database has been verified, the server was hosted on the 000Webhost. Therefore, registered users can access data from anywhere and at any time they need.

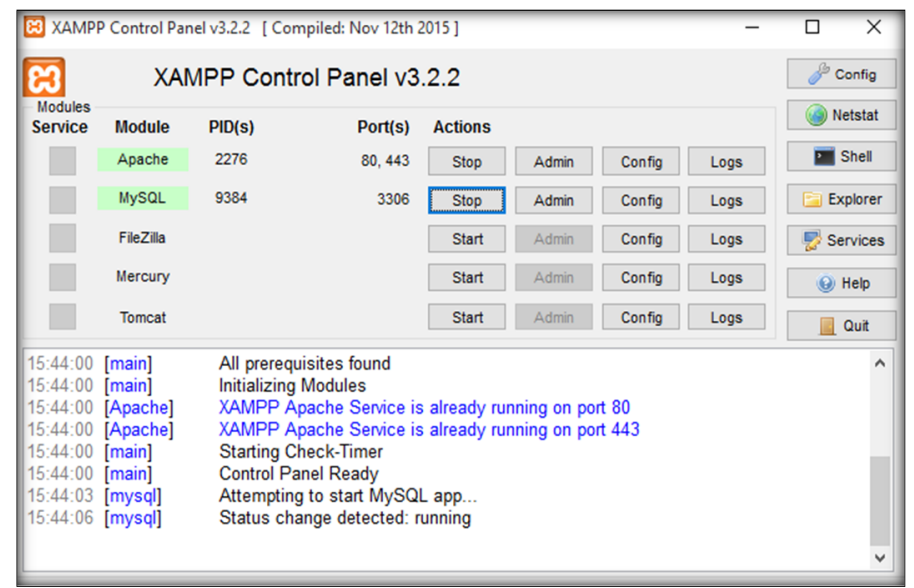

Figure 10. Local server panel control. 


\subsubsection{Sensor Node Implementation}

The sensor node, as shown in Figure 11(a), has temperature, humidity, $\mathrm{pH}$, and ultrasonic sensors, connected to a main board that allows processing the values measured by the sensors and sending them to NG using the module wireless NRF24L01. This node is connected to a LM2596 battery to maintain a stable voltage of $5.5 \mathrm{~V}$, which is supplied by the solar charge controller. It was also implemented inside an IP 65 protection box that gives enough resistance to light shocks, dust, and humidity, which could affect its operation.

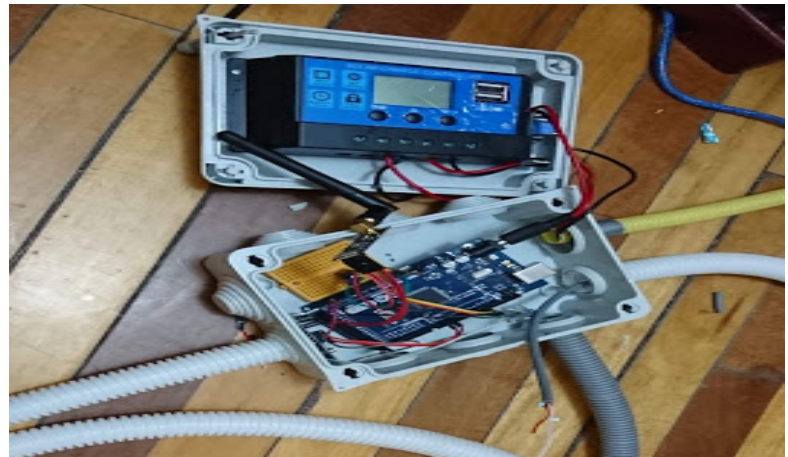

(a)

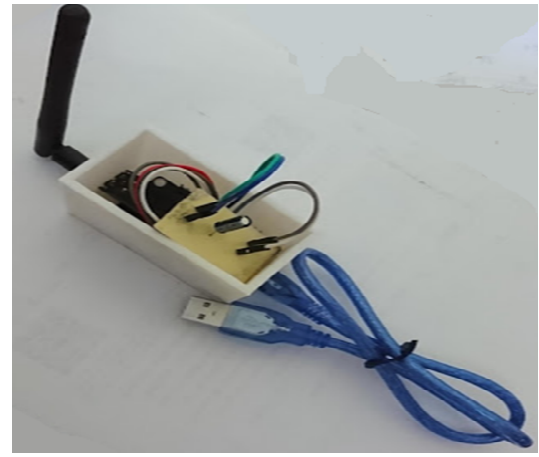

(b)

Figure 11. Implementation of Nodes: (a) Sensor Node. (b) Gateway Node.

\subsubsection{Gateway Node Implementation}

The Gateway Node contains an NRF24L01 module and an ESP8266 Wi-Fi module (Figure 11b). It receives data from the NS node and transmits to the cloud using Wi-Fi communication. The antenna of this module will be placed outside the bin to avoid losses of power in the wireless signal due to the structure of the container or the space interference that the waste could generate.

\subsection{Measurements}

Several tests were carried out in a real Eco-tacho in order to check and validate the operation of the smart system. Likewise, it was required to verify its stability when collecting the data and to evaluate the communication of all the modules.

For evaluating the data communication of each sensor, data were captured in NS and in NG as well and then compared as to whether the frames were the same and there were errors. Figure 12 shows data sent between both modules, increasing and decreasing residues as shown in Figure 13, in order to assess the sensors' performance and verify data communication.

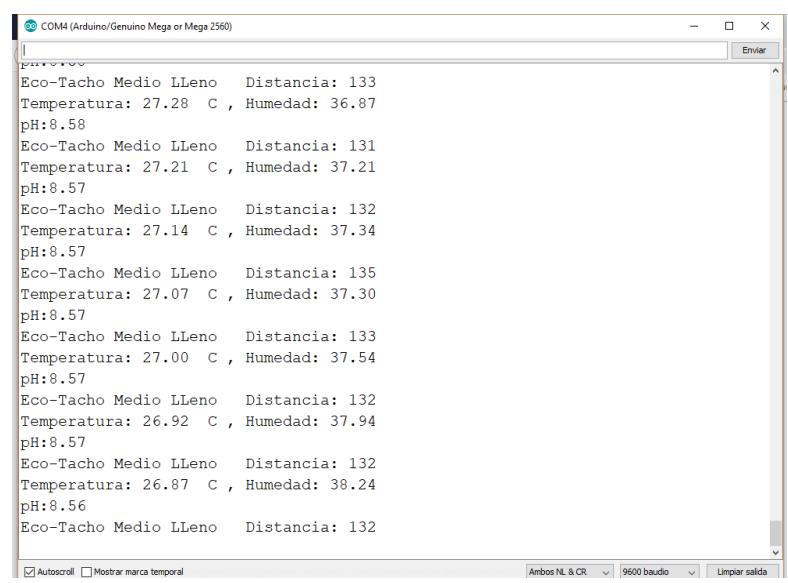

Figure 12. Data capture from NS and NG. 


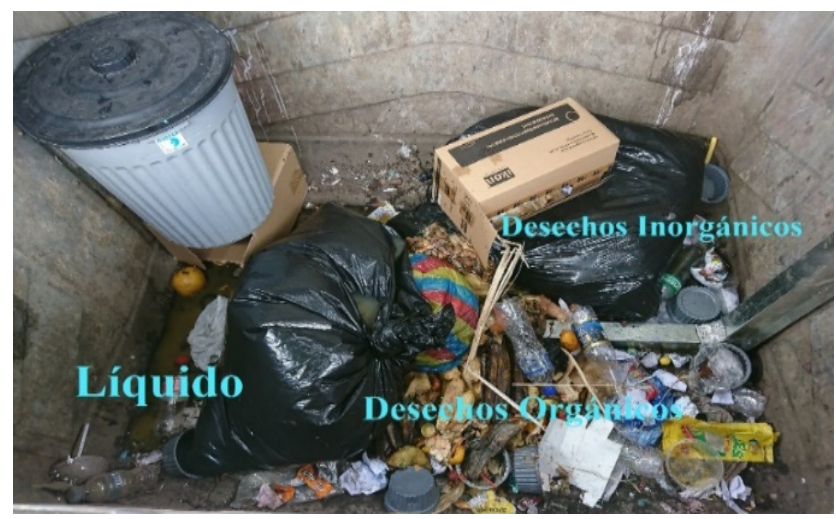

Figure 13. View inside the container.

Once the correct operation of the prototype had been verified, the next stage was to evaluate the access to the information through the web page in real time. To establish control levels and define alerts, it was necessary to analyze how each sensor obtains its respective measurement. For example, the $\mathrm{pH}$ sensor qualifies the dissolutions generated in the decomposition (leachates) with 15 levels. From level 0 to 6, it determines that the dissolution is acid, and from level 8 to level 14, it would correspond to the group of alkalis (basic), indicating in level 7 a neutral substance.

According to the current regulations for waste management, when a substance is between the values of 6.5 and 8.5 , it supposes that it is not harmful in any way; when, on the contrary, the low substance of 6.5 begins to corrode the metals, being the most harmful when the range falls below 4. On the contrary, if the substance exceeds 8.5 , carbonates and bicarbonates are generated, which produces gaseous detachments (bad odors) [24,25]. Regarding the level of filling of the container, it was established that when the ultrasonic sensor defines a value of 153, it means that the Eco-tacho is empty; if it registers a value of 95 , it means that the accumulation level is half, and when it is full, the sensor will register a value of 50, as shown in Table 3.

Table 3. Sensor levels to generate alerts.

\begin{tabular}{cccc}
\hline Sensor & Low Level & Medium Level / Neutro & High Level \\
\hline Ultrasonic & 153 (empty) & 95 (half full) & 50 (Full) \\
pH & 0 (acid) & 7 (neutro) & 14 (basic) \\
\hline
\end{tabular}

Regarding temperature and humidity levels, alerts were defined by making measurements in different scenarios, as observed in Section 3.2, showing waste decomposition behavior when these variables have a direct influence. Thus, it was established that if the temperature inside the Eco-tacho is $30^{\circ} \mathrm{C}$ or higher, the prototype must send an alert to the system.

In the case of humidity, if it exceeds $50 \%$, it will generate an alert indicating that the container can generate decomposition more quickly.

\section{Results}

\subsection{System Capacity for Data Transmission and Storage}

It was imperative to determine the bandwidth that each container consumes in data transmission and in order to define an estimate of the capacity required to install prototypes in all Eco-tachos implemented in Riobamba. Through packet captures in the communication between the NG node and the database, the number of bytes sent by each communication is determined and thus the amount of data storage that the WTS prototype needs in a certain time is established. It should be mentioned that in a real scenario, the system should continuously report its status so that in the event of exceeding the 
limit values at any time, the respective alerts can be sent. Therefore, it was defined that the system automatically generates a measurement every 5 minutes.

Data captures were carried out for $15.5 \mathrm{~h}$ in a row to determine an average load, since the ESPOCH has activities between 07:00 and 22:00. Table 4 shows the size of the data in bytes with respect to different time intervals. Measurements were carried out every 5 minutes, as mentioned above. This means that all prototype sensors automatically send an update of parameters to the server every 5 minutes, representing an average of 218 bytes, which in a full day represents $61.31 \mathrm{~KB}$ and $22.86 \mathrm{MB}$ per year. In this particular case, all the data generated by each container in one year correspond to $2.286 \%$ of the $1000 \mathrm{MB}$ offered by the chosen server.

Table 4. Transmission load for each container ${ }^{1}$.

\begin{tabular}{cc}
\hline Frequency & Data Average \\
\hline Per connection & 218 Bytes \\
Per day & 62,784 Bytes \\
Per month & $1.821 \mathrm{MB}$ \\
Per year & $21.854553 \mathrm{MB}$ \\
\hline
\end{tabular}

${ }^{1}$ Details of all these measurements are shown in the appendix section.

If we consider that all the prototypes that would be implemented in 1050 Eco-tachos in Riobamba would work in the same way and the same amount of data would be transmitted per connection, then 22.41 GB would be consumed per year (Table 5). This is a small size compared to the capacity of current systems.

Table 5. Transmission load for 1050 implemented containers.

\begin{tabular}{cc}
\hline Frequency & Data Average \\
\hline Per connection & $223.54 \mathrm{~KB}$ \\
Per day & $62.869 \mathrm{MB}$ \\
Per year & $22.41 \mathrm{~GB}$ \\
\hline
\end{tabular}

\subsection{Characterization of Variables}

Measurements were made on different days and hours with the intention of characterizing the phenomena that occur inside the container, so that the humidity and temperature conditions, as well as the level of filling, vary randomly. Since the WTS prototype constantly sends values to the database, there are infinite values from a statistical perspective. According to the central limit theorem, this is approximately normal [26,27].

It should also be considered that Riobamba is located in the Sierra region, on the Andean Cordillera of Ecuador, at a height of $2750 \mathrm{~m}$ above sea level and with a cold climate that varies during the course of the day. The environmental temperature is the highest from 12:00, with an average of $22^{\circ} \mathrm{C}$. Conversely, the coldest temperature could fall up to $0{ }^{\circ} \mathrm{C}$ at night.

Therefore, three (3) scenarios were defined on different days and at different times. Since we tried to determine how the decomposition changes due to temperature differences, the first time period was defined from 00:00 to 12:00 being the lowest and the highest temperature hours, correspondingly. Likewise, we considered from 2:00 to 14:00 and from 14:00 to 2:00, because those are periods where there is the greatest amount of waste accumulation. Therefore, it is possible to conclude how the conditions, inside the container, change due to the pressure of the waste itself. Measurements are shown in the following Tables 6-8. 
Table 6. Characterization of variables: Scenario 1 (00:00-12:00) ${ }^{2}$.

\begin{tabular}{ccccc}
\hline & Temperature & Humidity & pH & Fill Level \\
\hline Average & 15.5565 & 71.5357 & 8.8515 & 83.1986 \\
Variance & 1,3291 & 14.3696 & 0.4145 & 3.6523 \\
Standard deviation & 1.15285 & 3.7907 & 0.6438 & 1.9111 \\
\hline \multicolumn{4}{c}{${ }^{2}$ Details of all these measurements are shown in the appendix section. }
\end{tabular}

${ }^{2}$ Details of all these measurements are shown in the appendix section.

Table 7. Characterization of variables: Scenario 2 (02:00-14:00) ${ }^{3}$.

\begin{tabular}{ccccc}
\hline & Temperature & Humidity & pH & Fill Level \\
\hline Average & 19.9036 & 59.3619 & 9.4121 & 128.410 \\
Variance & 37.1045 & 424.243 & 0.8638 & 312.337 \\
Standard deviation & 6.0914 & 20.5971 & 0.9294 & 17.6730 \\
\hline
\end{tabular}

${ }^{3}$ Details of all these measurements are shown in the appendix section.

Table 8. Characterization of variables: Scenario 3 (14:00-02:00) ${ }^{4}$.

\begin{tabular}{ccccc}
\hline & Temperature & Humidity & pH & Fill Level \\
\hline Average & 22.6743 & 59.8065 & 10.1326 & 128.493 \\
Variance & 14.5535 & 279.985 & 1.0355 & 578.537 \\
Standard deviation & 3.8149 & 16.7327 & 1.0176 & 24.0528 \\
\hline
\end{tabular}

${ }^{4}$ Details of all these measurements are shown in the appendix section.

Regarding humidity, it was observed that the values are low during the week (less than $30 \%$ ) because waste collection is daily, while humidity level reaches values around $71 \%$ on weekends. This increase in humidity and combined with temperature factors caused a faster disintegration of organic waste, since waste remained inside the containers for more than two days. This change affects the chemical compositions sharply, as tables showed, exceeding the ninth $\mathrm{pH}$ level and generating bad odors.

These measurements are important because they validate that the most critical factor for chemical change in waste is temperature. Likewise, the difference regarding the days of waste collection with the addition of a temperature rise inside of the container is a determining factor for high decomposition, generating leachates and bad odors. We must bear in mind that leachate generation is only produced by organic waste decomposition, since the container has a hard lid on top and all its structure material avoids leaking other liquids from outside. Similarly, we must take into account that Scenario 1 (Figure 6) was measured on a weekend, when the university was closed, and hence there was no variation of waste amount, as it can be seen in the document "Characterization of variables: Scenario 1" in the appendix section. The measurements showed that as the temperature increased inside the Eco-tacho, the $\mathrm{pH}$ level of the leachate composition oscillated between level 7 and level 9. Therefore, leachates start generating gases and bad odors.

Scenarios 2 and 3, shown in Figures 7 and 8 correspondingly, were deployed on weekdays while the university was open, so there was a variation in waste accumulation, as it can be seen in the appendix section. For example, Scenario 3 was measured right after waste collection was done. In these scenarios, the measurements showed that the leachate chemical composition varied significantly from level 8 to level 12 due to the variation of temperature, humidity, and also the variation in the amount of waste. Consequently, odor and gas generation would also increase.

On the other hand, it was observed that humidity is also a determining factor, generating a faster decomposition with a high level. However, measurements in all scenarios showed that as the temperature increased, there is a reduction in humidity, thereby affecting the leachate $\mathrm{pH}$ sensor measurements. Conversely, pressure, which is generated by waste itself by accumulation, does not seem to be as critical a factor as the others. 
Consequently, the collection frequencies can be rectified depending, for example, on the areas where the most organic waste is generated, such as public markets and restaurants. However, routes could vary depending on different other factors, but the system will help make better decisions if it is needed, increasing waste collection up to two or three times a day to avoid critical levels.

For future projects, gas sensors could be included in order to analyze how odors and waste decomposition contribute to air pollution.

\subsection{Real-Time Alerts}

The amount of waste within the Eco-tacho was varied constantly and let time elapse so that the humidity and temperature values also vary and thus generate decomposition and leachate (Figure 12). This was done with the aim that the parameters measured by the sensors vary and the parameters reach the values defined as maximums that generate alerts in the system. Every time a parameter reached its control value, the system generated an alert that was shown in the specific user session.

\subsection{Communication Coverage}

This test aims to assess the communication coverage of the system and to define the best network topology with all implemented Eco-tachos in the city. Different topologies were considered, from a communication where each container is able to communicate with each other in an ad hoc network to a communication in a star topology where a group of containers send data to the cloud through a same access point.

In order to evaluate the signal quality and the operating distance of the system, four (4) scenarios were defined with different operating distances, taking into consideration the real distance that each Eco-tacho was placed in Riobamba. This separation distance is an average of $240 \mathrm{~m}$.

As it is shown in Table 9, various samples were taken for each range, in order to contrast all the measurements and avoid errors in the signal strength values. Hence, Eco-tacho spacing is in the range between excellent and good of signal quality.

Table 9. Communication coverage.

\begin{tabular}{|c|c|c|c|c|}
\hline Start Time & End Time & Communication Time & Distance [m] & Signal Strength \\
\hline $20: 41: 49$ & $20: 42: 55$ & 0:01:06 & \multirow{6}{*}{$0-170$} & \multirow{6}{*}{ Excellent } \\
\hline 20:44:01 & 20:45:08 & 0:01:07 & & \\
\hline $20: 45: 08$ & $20: 46: 15$ & 0:01:07 & & \\
\hline $20: 53: 13$ & $20: 54: 19$ & 0:01:06 & & \\
\hline 20:59:11 & $21: 00: 17$ & 0:01:06 & & \\
\hline 21:01:24 & 21:02:30 & 0:01:06 & & \\
\hline $21: 03: 36$ & $21: 04: 56$ & 0:01:20 & \multirow{6}{*}{$170-326$} & \multirow{6}{*}{ Good } \\
\hline 21:05:49 & 21:07:10 & $0: 01: 21$ & & \\
\hline 21:08:19 & 21:09:12 & 0:00:53 & & \\
\hline $21: 10: 18$ & $21: 11: 24$ & 0:01:06 & & \\
\hline 21:12:31 & $21: 13: 37$ & 0:01:06 & & \\
\hline 21:14:43 & 21:15:50 & 0:01:07 & & \\
\hline $21: 16: 59$ & 21:19:10 & 0:02:11 & \multirow{6}{*}{$326-480$} & \multirow{6}{*}{ Low } \\
\hline $15: 48: 35$ & $15: 49: 41$ & 0:01:06 & & \\
\hline $15: 51: 54$ & $15: 53: 00$ & 0:01:06 & & \\
\hline $16: 33: 26$ & $16: 35: 29$ & 0:02:03 & & \\
\hline $16: 36: 31$ & $16: 37: 57$ & $0: 01: 26$ & & \\
\hline $16: 45: 28$ & $16: 47: 01$ & 0:01:33 & & \\
\hline- & - & - & $>480$ & Non-Operational \\
\hline
\end{tabular}


On the other hand, an ad hoc network was established with 4 different communication cards emulating the same amount of data, transmitting at the same established frequency. This showed that each card had considerable processing for sending its own generated information and forwarding data from other cards to the next jump. Consequently, the network capacity would be decreased depending on the number of nodes included in the network, and also, each node would need more processing. This idea matches with the results in [28], where different conditions for ad hoc networks were studied such as the type of traffic, the distance, and the interaction between nodes, reaching the conclusion that the degradation of an ad hoc network occurs due to the increase in nodes and the physical size of the network. The shortcomings for an ad hoc network with a huge number of nodes are a large decrease in transmission speed, and each node could not send and receive data at the same time in order to avoid interferences with other nodes. Therefore, star topology was chosen to take advantage of the access points found in the city and allow the system can be more scalable.

\section{Discussion and Conclusions}

The impact of this project is the implementation of the smart system in Riobamba contributing advantages compared to other studies such as the creation of a low-budget, low-consumption, and free-band communication system, avoiding payments for spectrum use or data transmission. Similarly, the use of elements such as high-definition cameras was evaded so that there is no high consumption of bandwidth. Hence, we achieved a system with an efficient use of both bandwidth and storage. Thus, the prototype consumes only $2.18 \%$ per year of the total capacity of to the cloud server by sending updates of all parameters every 5 minutes. This is a minimum space requirement compared to the capacity of current systems. Likewise, an Eco-tacho location system was proposed through the web platform, achieving independence from GPS devices to prevent unnecessary energy consumption.

The reliability of the communication is between good and excellent. Packet loss begins at a distance greater than $200 \mathrm{~m}$; for this reason, Wi-Fi connectivity was used for communication with the cloud server, taking advantage of the Wi-Fi access points installed in the city.

On the other hand, it was found that temperature is a critical factor in waste decomposition, despite Riobamba having a cool temperature. Tests showed that a temperature over $16{ }^{\circ} \mathrm{C}$ inside the container is enough to accelerate waste decomposition if the collection frequency is greater than $24 \mathrm{~h}$.

Finally, this project contributes to the country's sustainable development and technological innovation strategies to promote the construction of digital territories and smart cities $[13,14]$. Future studies could focus on a recollection system, which can obtain information from this project and reroute and improve frequency collection autonomously.

Author Contributions: Supervision and methodology, D.V.-C.; implementation, P.M. and J.P.; data curation, P.M. and Johana Panchi; formal analysis, D.V.-C., P.M. and J.P.; validation, R.L.-Y. and J.R.; writing-Original draft preparation, D.V.-C., P.M., and Johana Panchi; writing-Review and editing, D.V.-C., R.L.-Y., and J.R. All authors have read and agreed to the published version of the manuscript.

Funding: This research received no external funding.

Acknowledgments: We would like to thank Victor Herrera-Pérez and Jefferson Ribadeneira for their recommendations for the final manuscript and Faculty of Informatics and Electronics of Escuela Superior Politécnica de Chimborazo, for its support throughout this research.

Conflicts of Interest: The authors declare no conflict of interest.

\section{References}

1. Eltelégrafo. El Telégrafo-En Nueva York la Recolección de Basura es un Reto. Available online: https: //www.eltelegrafo.com.ec/noticias/planeta/1/en-nueva-york-la-recoleccion-de-basura-es-un-reto (accessed on 14 March 2019).

2. ITONGADOL. En Afula, \& Quot; Contenedores Inteligentes \& Quot; de Residuos Avisan Cuando Están Llenos. Available online: http://www.itongadol.com.ar/noticias/val/89575/en-afula-contenedores-inteligentes-deresiduos-avisan-cuando-estan-llenos.html (accessed on 14 March 2019). 
3. Aazam, M.; St-Hilaire, M.; Lung, C.H.; Lambadaris, I. Cloud-Based Smart Waste Management for Smart Cities. In Proceedings of the IEEE 21st International Workshop on Computer Aided Modelling and Design of Communication Links and Networks (CAMAD), Toronto, ON, Canada, 23-25 October 2016; pp. 188-193. [CrossRef]

4. Environment Ministry of Ecuador. Programa "PNGIDS" Ecuador. Available online: https://www.ambiente. gob.ec/programa-pngids-ecuador/ (accessed on 22 March 2019).

5. Alire, L.; Ramos, J. Los Contenedores de Basura son un Riesgo para la Salud-Diario Correo. Available online: https://diariocorreo.pe/edicion/arequipa/los-contenedores-de-basura-son-un-riesgo-para-la-salud738967/ (accessed on 15 March 2019).

6. GADMR. Dirección de Higiene socializó plan de contenerización y sistema de recolección de desechos sólidos-Municipio Riobamba. Available online: http://www.gadmriobamba.gob.ec/index.php/noticias/ boletines-de-prensa/503-direccion-dehigiene-socializo-plan-de-contenerizacion-y-sistema-de-recoleccionde-desechos-solidos (accessed on 18 March 2019).

7. GADMR. EcoTachos En La Ciudad de Riobamba. 2018. Available online: https://www.compraspublicas. gob.ec/ProcesoContratacion/compras/PC/bajarArchivo.cpe?Archivo=e2fC62Cyub3wtKrxW1faZde7zNp_ -LLO5PnRbBWzapw (accessed on 18 March 2019).

8. Khatoun, R.; Zeadally, S. Smart Cities: Concepts, Architectures, Research Opportunities. Commun. ACM. 2016, 46-57. [CrossRef]

9. Bătăgan, L. Smart Cities and Sustainability Models. Inform. Econ. 2011, 15, 80-87.

10. Leccese, F.; Leonowicz, Z. Intelligent Wireless Street Lighting System. In Proceedings of the 11th International Conference on Environment and Electrical Engineering, Venice, Italy, 18-25 May 2012; pp. 958-961. [CrossRef]

11. Marino, F.; Leccese, F.; Pizzuti, S. Adaptive Street Lighting Predictive Control. Energy Procedia 2017, 111, 790-799. [CrossRef]

12. Mangiatordi, F.; Pallotti, E.; Del Vecchio, P.; Leccese, F. Power Consumption Scheduling for Residential Buildings. In Proceedings of the 11th International Conference on Environment and Electrical Engineering, Venice, Italy, 18-25 May 2012; pp. 926-930. [CrossRef]

13. Ministerio de Telecomunicaciones. Libro Blanco de Territorios Digitales En Ecuador; Mintel: Quito, Ecuador, 2019.

14. Mardacany, E. SMART CITIES CHARACTERISTICS: Importance of Built Environment Components. IET Semin. Dig. 2014, 2014, 15564. [CrossRef]

15. Medvedev, A.; Fedchenkov, P.; Zaslavsky, A.; Anagnostopoulos, T.; Khoruzhnikov, S. Waste Management as an IoT-Enabled Service in Smart Cities Alexey. In Proceedings of the Internet of Things, Smart Spaces, and Next Generation Networks and Systems, RuSMART, Rusia, 26-28 August 2015; Volume 9247, pp. 104-115. [CrossRef]

16. Sharma, N.; Singha, N.; Dutta, T. Smart Bin Implementation for Smart Cities. Int. J. Sci. Eng. Res. 2015, 6, 787-791.

17. Anagnostopoulos, T.; Zaslavsky, A.; Kolomvatsos, K.; Medvedev, A.; Amirian, P.; Morley, J.; Hadjieftymiades, S. Challenges and Opportunities of Waste Management in IoT-Enabled Smart Cities: A Survey. IEEE Trans. Sustain. Comput. 2017, 2, 275-289. [CrossRef]

18. Arguello, H. La Descomposición de La Materia Orgánica y Su Relación Con Algunos Factores Climáticos y Microclimaticos. Agron. Colomb. 1991, 8, 384-388.

19. Diaz, L.F.; de Bertoldi, M.; Bidlingmaier, W. Compost Science and Technology; Elsevier Science: Amsterdam, The Netherlands, 2011.

20. Encarnación, G.; Kiss, G. Los Productos y Los Impactos de La Descomposición de Residuos Sólidos Urbanos En Los Sitios de Disposición Final. Gac. Ecológica 2006, 79, 39-51.

21. Sistema Integrado de Seguridad ECU911. Available online: www.ecu911.gob.ec (accessed on 8 April 2020).

22. Corral-De-Witt, D.; Carrera, E.V.; Matamoros-Vargas, J.A.; Munoz-Romero, S.; Rojo-Álvarez, J.L.; Tepe, K. From E-911 to NG-911: Overview and Challenges in Ecuador. IEEE Access 2018, 6, 42578-42591. [CrossRef]

23. Cordovez, B. Gestión de Desechos Sólidos Será Controlada a Través de Ordenanza. Diario Los Andes, 4 May 2019.

24. Najera Aguilar, H.A. LIXIVIADOS ¿Qué Son, Cómo Se Clasifican?¿Qué Son, Cómo Se Clasifican? (Parte 1) LIXIVIADOS Parámetro Intervalo de Valores $(\mathrm{Mg} / \mathrm{L})$ (Excepto Donde Se Indica) Parámetro Intervalo de va Lores (Mg/L). Available online: https://www.unicach.mx/_/ambiental/descargar/Gaceta4/Lixiviados.pdf (accessed on 4 May 2019). 
25. Espinosa Lloréns, M.; López, M.; Pellón, A.; Robert, M.; Diaz, S.; González, A.; Rodríguez, N.; Fernández, A. Análisis Del Comportamiento de Los Lixiviados Generados En Un Vertedero de Residuos Sólidos Municipales de La Ciudad de La Habana. Rev. Int. Contam. Ambient. 2010, 26, 313-325.

26. Eugene, O. La Media vs. la Mediana-Ayuda de Zendesk. Available online: https://support.zendesk.com/hc/ es/articles/228989407-La-media-vs-la-mediana (accessed on 23 May 2019).

27. Soporte de Minitabß18. El Teorema del Límite Central: Las Medias de Muestras Grandes y Aleatorias Son Aproximadamente Normales. Available online: https://support.minitab.com/es-mx/minitab/18/help-andhow-to/statistics/basic-statistics/supporting-topics/data-concepts/about-the-central-limit-theorem/ (accessed on 24 May 2019).

28. Li, J.; Blake, C.; De Couto, D.S.; Lee, H.I.; Morris, R. Capacity of Ad Hoc Wireless Networks. In Proceedings of the 7th Annual International Conference on Mobile Computing and Networking, Rome, Italy, 16-21 July 2001; pp. 61-69. [CrossRef]

C 2020 by the authors. Licensee MDPI, Basel, Switzerland. This article is an open access article distributed under the terms and conditions of the Creative Commons Attribution (CC BY) license (http://creativecommons.org/licenses/by/4.0/). 